\title{
Sustainable and commercial development of aquaponics through the certification in Europe
}

\author{
Maria José Palma Lampreia Dos-Santos \\ Department of Social Sciences - DINÂMIA'CET- ISCTE- IUL Escola Superior de Comunicação Social - Instituto Politécnico de Lisboa, \\ Campus de Benfica, 1649-026 Lisboa, Portugal \\ E-mail address: msantos@escs.ipl.pt
}

\begin{abstract}
Aquaponics is nowadays a sustainable practice of producing food with a short supply chain and with a very interesting need for development towards the sustainable production of foods. The main aim of this paper is to analyses the present situation of aquaponics in terms of commercial development and to define the main strategies to be overcome in order to promote its development. The methodology used is a systematic literature review based on the recent indexed references. The main results outline confirm besides aquaponics presents many benefits in terms of social, economic and environmental, therefore, so, its development must involve all the stakeholders from research to public decision-makers and consumers.
\end{abstract}

Keywords - aquaponics; organic certification; sustainable production; aquaculture; hydroponics; sustainability

\section{Introduction}

Systems that grow additional crops by utilizing by-products from the production of the primary species are referred to as integrated systems (Goddek et al., 2019; Greenfeld et al., 2019). If the secondary crops are aquatic, or if terrestrial plants grown in conjunction with fish, this integrated system is referred to as an aquaponic system (Rakocy, 2012; DosSantos and Diz, 2019; Dos-Santos 2018; Dos-Santos et al., 2020). Aquaponics is a sustainable eco-friendly food production system (Shafahi \& Woolston, 2014) where nutrient-enriched water from fish tanks is recirculated and used to fertilize vegetal production beds, thus making good use of the valuable nutrients that in conventional aquaculture systems are discarded. Aquaponics systems are typically designed to achieve maximum yields with minimal water, fertilizer, and energy use within a relatively small land footprint in a sustainable way of using all the resources. (COST FA1503 Action; Dos Santos, 2016; Miličić et al., 2017; Dos-Santos, 2018).

Aquaponics is considered a sustainable agricultural production system (Dos-Santos, 2018, König et al., 2016;
Goddek et al., 2019) that does not deplete any non-renewable resource essential to agriculture, in order to sustain the agricultural practices in the future. Francis et al., (2003) add that sustainable agricultural production can be achieved by resembling natural ecosystems and "designing systems that close nutrient cycles", which is one of the main characteristics of aquaponics (Goddek et al., 2019; Kledal et al., 2017).

The sustainability of aquaponic production was in general recognized across the world and directly or indirectly referred, namely by:

1) The Food and Agriculture Organization from the United Nations has recognized aquaponics as a future sustainable food production practice;

2) The Millennium Development Goals for 2030 supported by the United Nations recommend to improve progressively, by 2030 , the efficiency of global resources in consumption and production, and strive to decouple economic growth from environmental degradation, in line with the 10-year round of sustainable production and consumption programs, with developed countries assuming the leadership (United Nations Millennium Goals; 2017); 
3) The Europe 2020 strategy sets out three mutually reinforcing priorities, namely: a) smart growth: developing an economy based on knowledge and innovation; b) sustainable growth: promoting a more resource-efficient, greener and more competitive economy. c) Inclusive growth: fostering an economy with high levels of employment that ensures social and territorial cohesion;

4) The European Hub of Aquaponics supported by the European Union - The COST FA1305 has also developed relevant research proving that aquaponics is a sustainable practice in its four dimensions, namely, $i$ ) economic, because it will allow the development of a sustainable and organic agriculture practice with impacts on the gross added value; $i$ ) Social because it will allow employment growth and social inclusion, in addition to commercial development; iii) environmentally sustainable because it will allow the creation of fresh organic foods in an urban environment, avoiding long supply chains, loss of efficiency and $\mathrm{CO} 2$ emissions associated with them (Dos-Santos, 2018);

5) These results were also confirmed by Dos Santos (2016) who presents aquaponics as a pre-requisite from smart cities of the future. These authors also referring policies constraints that are nowadays strong restrictions on the development of organic aquaponics. In this context, it should be noted that although the production of fish and vegetables in aquaponics fulfills all the requirements of organic production, it is not recognized as such in Europe (Dos Santos, 2016; Miličić et al., 2017).

Besides these achievements according to Miličić et al., (2017) aquaponics companies, aquaponics suppliers and many startup businesses are taking the first steps towards commercial aquaponics production and there are also a few country governmental initiatives around the world. These authors highlight and confirm the main developments of aquaponics in Europe and across the world.

From a consumer point of view, Tomić et al. (2016) analyzed the main factors that determine fresh fish consumption applied to Croatia. The authors refer to the increasing importance of the consumer of fresh fish in recent years across the world. Renko et al. (2014) analyzed the main attitudes as basis and segmenting fresh fish consumers applied to Croatia and had concluded that the identification of different attitudes and barriers towards fresh fish consumption and socio-demographic features may provide an opportunity for the fish producers to develop marketing strategies that will meet demands of different consumers (Greenfeld et al. 2019).

Miličić et al., (2017) analyzed the consumers' perceptions of aquaponics in Europe and the main aim was to estimate consumers' knowledge about aquaponics and their acceptance of aquaponics products in different European regions. The main results confirm three different clusters of potential consumers of aquaponics products. The results show that, on average, attitudes towards aquaponics were positive, showing no significant differences between those who already knew about aquaponics and those who only heard about it.
This contribution also confirms the acceptance by stakeholders about aquaponics by consumers, researchers, producers and the public in general based of their multiple benefits for sustainability of food production and food supply chain and for the society in general (Konig et al., 2016; 2018). Despite this, there are still unresolved problems that hamper the development of aquaponics in Europe by commercial companies, namely, the organics contradictory rules prohibiting certification of aquaponics in Europe. In this context, we consider the aspirations of aquaponics producers and commercial enterprises to be legitimate, since this is a form of agriculture and fish and vegetable production whose characteristics are even much more restricted than organic production (in particular the use of organic phytopharmaceuticals approved for aquaponics which is more restricted because of fish feed).

The fact that aquaponics has numerous advantages compared to traditional agriculture, aquaculture and hydroponics on their own should enable aquaponics to find a rightful and expanding niche in the organic/sustainable food market but it is being held back because of certification rules that do not fit.

\section{Aquaponic production in Europe}

Despite the aquaponics was an ancient technology already used by the Babylonians in their suspended gardens and by the Aztec civilization with their cities floating foods, where food of animal and vegetable origin was produced when they were stripped of their lands (Araújo, 2015), nowadays becomes more and more necessary due to the need to adjust the food supply in the face of a growing demand of food, where the share of total population living in cities exceeded 50\% (Dos Santos, 2016; Dos-Santos and Diz, 2019) and is continuing to increase (Food and Agriculture Organization, 2017).

Aquaculture and aquaponics are also receiving increased interest globally as a sustainable food production method. According to Thorarinsdottir (2017) the commercially available systems of aquaponics are mainly based on the research carried out by Rakocy and his coworkers at the University of Virgin Islands (Rakocy, 2012) however, most aquaponics systems so far are small hobby, while others are research systems; touristic investment; but the start-ups are taking the first steps in Europe (Miličić et al., 2017) besides the high grade of development in the United States of America (Lowe et al., 2015). These last authors present the main developments of aquaculture and aquaponics around the world.

The main reason for the development of aquaponics is because combines the advantages of hydroponics with aquaculture. By ecological awakening of the whole community and by the broadening of the aquacultural activity, the influence of the aquaculture on the environment is more questionable (Slišković et al., 2003). Piria et al., (2016) have observed the decline in European eel stock Anguilla anguilla (L.) on the European continent and propose 
the development of a management plan for the Eastern Mediterranean and regular monitoring. This shortage associated with the presence of heavy metals in seawater means that aquaculture has grown significantly, especially in the more developed countries (FAO, 2017). With the development of aquaculture with the combination of hydroponics these effects where reduced or eliminated.

Nichols (2008) and Blidariu and Grozea (2011) sustain that there is a possibility to increase the economic efficiency of aquaculture by selling the crop as a certified organic crop because it is produced entirely from natural manure (fish waste). The system involves no control of root pathogens, as these are controlled biologically by the broad spectrum of antagonistic micro-organisms that develop in the natural environment.

On the other hand, this agricultural system of sustainable food reduces the inputs land, machinery, fuel, and allows a food supply chain with more efficiency, from producers to consumers directly, as well the production system.

Villarroel et al. (2016) conducted a survey in Europe to aquaponics practitioners. According to the results, the main priorities in aquaponics must addressed the personal priorities in working with aquaponics. Approximately $25 \%$ of respondents agreed that they thought aquaponics could help to grow their own food, improve personal health, or improve the health of members of the community. Most respondents from all over Europe, which agreed or strongly agreed to use aquaponics in education (98\%), to improve the sustainability of food production (96\%), to aid in development $(68.6 \%)$, and to decrease the effects of climate change $(68 \%$ agreed or strongly agreed). The results of that survey suggest that the research base in aquaponics in Europe is still stronger than profit-based activity. This is probably also due to the existing regulatory voids regarding the commercialization of aquaponic products (Joly et al., 2015) and long administrative authorization processes. Overall, they estimate that there are approximately 20 large commercial aquaponic operations $\left(>1500 \mathrm{~m}^{2}\right)$ that have recently opened or are under construction in Europe, most of them in an urban environment. It remains to be seen whether these efforts confirm a shift towards sustainable development of a profitable European aquaponics industry.

\section{Towards aquaponics organic certification}

Organic certification appears to be a natural step for an aquaponics producer since the whole system is based on holistic thinking in terms of recycling, lowering the resource intake and securing zero pollution. However, the present organic regulatory regime does not have any standards or regulations for certifying organic aquaponics. The recirculating aquaculture systems (RAS) technology itself is forbidden under the present organic regulation, which seems to be more of political and economic protection of the extensive open pond systems prevalent in organic fish production rather than having anything to do with fish welfare or secure a cleaner aquatic environment. Likewise, the hydroponic production technology prevalent in modern horticulture is also prohibited (Goddek et al., 2019).

It is only possible to have an aquaponic production system completely certified organic if a non-holistic approach is made, meaning a certification towards the organic fish- and horticulture regulation is made separately. Firstly, the plants must be grown in soil. Secondly, the fish produced must be fed with certified organically produced fish feed, and thirdly the fish can only be produced in a RAS system if the fish are sold as fingerlings for further growth in open-air pond systems certified organic. However, if aquaponic produce gains markets and moves into larger-scale production systems, it seems indisputably; that the organic farm movement will need to revise its present regulatory regime focusing on specific technologies rather than having a more principle-based approach allowing for new resource productive and holistic production systems such as aquaponics (Konig et al., 2018).

The present regulatory framework for organic fish and horticultural production in the EU is regulated by the Council Regulation (EC) No. 834/2007 whereas more detailed rules are regulated by the Commission Regulations (EC) No. 889/2008, and (EC) No. 710/2009.

\section{Horticultural production}

For horticultural products, the specific EU regulation preventing products produced under 'classical' aquaponics systems to obtain organic certification, are the following: 834/2007 Regulation (12): Plants should preferably be fed through the soil eco-system and not through soluble fertilizers added to the soil and Regulation 889/2008 Article. (4): Hydroponic production is prohibited.

Since the 'classical' aquaponics production systems are based on a soilless hydroponic technology, the plants produced under such a system cannot be certified as organic. This leaves aquaponics producers with the only option to adopt culturing practices in aquaponics applying soil or other types of growth media allowed within organic products such as peat, various compost products, etc. However, since the RAS technology itself is forbidden under organic production, the fertilizer supplied to the plants from the fish part in aquaponics can in principle not be recycled back to the sump tanks and bio-filters. It must be recycled within the plant loop until used, or at some point be discharged out of the aquaponics system.

\section{Aquaculture production}

For organic aquaculture, the production is regulated by Commission Regulations of $889 / 2008$ and 710/2009. In Paragraph 11 of Commission Regulation (2009) recirculating technology is clearly prohibited in organic aquaculture, except for the specific production of fingerings in hatcheries and nurseries for further growth in open-air pond systems. 
Since recirculating technology is at the core of the aquaponics production system it is at present not possible to get a complete organic certification of an aquaponics system, if all of the finishing product is to be sold for the consumer market.

\section{Paragraph 11}

Recent technical development has led to increasing use of closed recirculation systems for aquaculture production, such systems depend on external input and high energy but permit reduction of waste discharges and prevention of escapes. Due to the principle that organic production should be as close as possible to Nature, the use of such systems should not be allowed for organic production until further knowledge is available. Exceptional use should be possible only for the specific production situation of hatcheries and nurseries.

Likewise, the organic regulation on fish density in open ponds is mainly made to secure a discharge of fish manure to the aquatic environment at a minimum. Questions on fish welfare are, therefore, an indirect matter related to their well-being based on the level of fresh water supply to the ponds. The levels of stock density in organic aquaculture are often 1/4 to $1 / 3$ of the stock density in modern RAS systems, and therefore from an economical aspect not very feasible as well as to what the RAS technology can actually uphold of fish stockings.

\section{Future of organic aquaponics and its certification}

The crux for aquaponics producers to get organic certification in the future lies in the acceptance of the recirculating technology within organic regulation itself, as well as presenting aquaponics as an ideal closed-loop, non-pollute, and holistic food production system.

Short-term strategies in this regard could be to:

1) View aquaponics as a farm-based on a necessary harmony and biomass ratio between husbandry (the fish), and a soilbased horticultural production as the field turning waste into valuable resources and providing a food production with no discharges to the environment.

2) Work towards a specific regulation on aquaponics. This would imply allowing recirculating technology such as RAS, and an intensification of the fish production. Fish intensification is already regulated by the organic regulation but is based on an extensive open-air pond system and the question of discharge of fish manure to the aquatic environment.

Paragraph 24 in the Commission Regulation (2009) opens up for an interpretation that such steps for a revision in the organic rules could be allowed. Especially the last four lines in Paragraph 24 imply that national initiatives could be taken with the aim of improving the common EU regulation on organic aquaculture. This would require a more dedicated willingness in the organic movement to commence a process in this direction, but unfortunately, this dedication and willingness do not seem to exist at present.

\section{Paragraph 24}

Organic aquaculture is a relatively new field of organic production compared to organic agriculture, where long experience exists at the farm level. Given consumers' growing interest in organic aquaculture products further growth in the conversion of aquaculture units to organic production is likely. This will soon lead to increased experience and technical knowledge. Moreover, planned research is expected to result in new knowledge in particular on containment systems, the need of nonorganic feed ingredients, or stocking densities for certain species. New knowledge and technical development, which would lead to an improvement in organic aquaculture, should be reflected in the production rules. Therefore, provision should be made to review the present legislation with a view to modifying it where appropriate.

\section{Perspectives}

The commercial activity development of aquaponics starts from a point of considerable weakness and disadvantage in the market because in the EU and in the majority of the countries legislation is still generally unfamiliar, confusing and contradictory mainly within the decision-makers and the beneficial aspects resulting from products of aquaponics production are unknown for the public in general. Chopin (2012 and 2013 ) asks "How can we inform aquaculturists, scientists, regulators, decision-makers and the general public that there are other types of aquaculture systems in the world?" The first part of this question that involves researchers, practitioners and their dissemination to consumers is already partially solved by the EU Aquaponics Hub created by COST FA 1305 that aims to the development of aquaponics in the EU, by leading the research agenda through the creation of a networking hub of expert research and industry scientists, engineers, economists, aquaculturists and horticulturalists, and contributing to the training of young aquaponic scientists. (COST FA 1305, 2017). But the problem remains with the public decision-makers.

At the moment within the Strategy of Lisbon the European Parliament acquires more strong powers in all the matters to be legislated; and after Strategy of Europe 2020 the European Commission (EC) and the European Council (ECC) and the European Parliament (EP) acquired more strong responsibilities in order to achieve the goals they set themselves.

According to that confusing, incipient, incomplete and promoting legislative framework among the European countries from EU we suggest reinforcing, achieve and complete the COST Action goals and targets, namely, the promotion and the effective commercial development of aquaponics and the organic certification, as well the sustainable aquaculture. Also, the development of a strong and new project sponsored with the high and honorable sponsorship by the European Institutions (EP) /(EC)/(ECC) and with the involvement of European researchers qualified 
in this subject. This project could be in similar terms for example from the previous experience from Dos-Santos, (2013) or IP/B/AGRI/IC/2012-065 (2013) from the European Parliament.

As such, aquaponics has not yet gained the consumer's deserved perception (Miličić et al., 2017). To overcome this barrier, which new aquaponics entrepreneurs and producers have to overcome in order to put their products on the market side by side with organic certification products, it is essential that steps are taken to regulate organic production in order to make feasible the certification of the two aquaponic elements - fish and plants.

\section{Discussion}

The European Union could play a crucial role in the inclusion of aquaponics in organic certification, as this will contribute to the established objectives of developing technology solutions for sustainable aquaculture (EESC, 2011, 2014, 2017) and sustainable agriculture within European territory (European Parliament, 2016). So, we strongly suggest a new task force like the last IP/B/AGRI/IC/2012-065 requested by the European Parliament to solve the many legislative gaps and uniform legislation promoted by the European Institutions with the researchers and decisions-making.

On the other hand, from the perspective of economic agents, the increasing association of aquaponics producers will tend to lead to greater pressure on regulators, as occurred in the USA, which may accelerate the process of including aquaponics in organic certification.

In the face of resistance from regulators, aquaponics producers in the US have shown that several phytopharmaceuticals, commonly used in organic farming, have been found to be harmful in aquaponics, with severe impacts on fish mortality in aquaponics systems. These impacts on the animal side of the ecosystem have raised some doubts about the toxicity and safety of some substances used in organic agriculture (Goddek et al., 2019).

In this context, aquaponics presents itself as a self-regulating coupled ecosystem, which presents greater and more visible guarantees to the consumer, from the point of view of its perception, since it is a simple and easy to learn concept that keeping fish and plants alive and thriving in the same circuit is a biological indicator of total production safety (Komives and Junge, 2018).

The disclosure of these details by producer associations may, like the occurrences in the USA, trigger the acceleration of the inclusion of aquaponics in the organic certification, especially in relation to the vegetable side of production (Lowe et al., 2015).

As a result, and by understanding the food safety advantages such as the absence of contamination and medication and the profound advantages of environmental sustainability, the aquaculture side of aquaponics may, in the short or medium term, also be certifiable as organic. More research and more scientific data may become a strong contribution in this direction (Dos-Santos, 2018).

At the same time, there are also some plans by producer associations to temporarily circumvent the immediate need for organic certification of their products, through the creation of private "aquaponics products" certifications, through the development of specific aquaponics production standards, providing a specific seal to producers who demonstrate the strict compliance of these criteria. Through a strong marketing campaign directed to consumers, this seal and the concept of aquaponics could be advertised, in a widespread and well-structured way, making the aquaponics products credible and easily identifiable by the seal's affixing (Goddek et al., 2019.

In any case, the need to increase global production of animal protein and more natural plant production, as well as increasing consumer demands and environmentally sustainable food production, will put increasing pressure on regulators to place aquaponics in the midst of organic certification (Goddek et al., 2019).

\section{Conclusions}

The present situation of aquaponics in institutional terms outline confirm besides aquaponics presents many benefits in terms of social, economic and environmental, your development must involve all the stakeholders from research to public decision-makers and consumers. Based on the problems unsolved and gaps in general with aquaponics legislative matters and in special with organic certification of aquaponics we strongly recommend a new task force by all the European public decisions makers at European and regional level and also the high and honorable sponsorship by the European Institutions (EP)/(EC)/(ECC) and with the involvement of European qualified researchers and production parties in this subject.

\section{Acknowledgment}

The author thanks two anonymous reviewers for critically reading the manuscript and for their valuable suggestions and comments that substantially helped to improve and clarify this paper.

\section{References}

Araújo, A. D. F. (2015). Integração de plantas com espécies nativas de peixes em sistema de aquaponia. MS Thesis. https://repositorio.ufsc.br/xmlui/handle/123456789/160671 (accessed on October 11, 2019)

Blidariu, F., \& Grozea, A. (2011). Increasing the economical efficiency and sustainability of indoor fish farming by means of aquaponics - review. Scientific Papers Animal Science and Biotechnologies 44(2), 1-8. 
COST FA1305, 2015. Memorandum of Understanding, https://www.cost.eu/actions/FA1305/\#tabs/Name:overview (accessed on October 11, 2019)

Chopin, T. (2012). Seaweed aquaculture provides diversified products, key ecosystem functions. Part II recent evolution of seaweed industry. Global Aquacult Adv, 14, 24-27. https://www.aquaculturealliance.org/advocate/seaweedaquaculture-provides-diversified-products-key-ecosystemfunctions-part-2/ (accessed on October 11, 2019)

Chopin, T. (2013). Integrated multi-trophic aquacultureancient, adaptable concept focuses on ecological integration. Global Aquacult Advocate, 16, 16-19.

DOI: $\underline{10.1007 / 978-1-4614-5797-8 \quad 173}$

Dos-Santos, M. (2013). Semi-subsistence farming: value and directions for development: Case study Portugal. In: European Parliament Study IP/B/AGRI/IC/2012-65: Portugal. European Parliament.

Dos Santos, M. J. P. L. (2016). Smart cities and urban areasAquaponics as innovative urban agriculture. Urban Forestry \& Urban Greening 20: 402-406.

DOI: $\underline{10.1007 / 978-1-4614-5797-8 \_173}$

Dos Santos, M. J.P.L. (2018). Nowcasting and forecasting aquaponics by Google Trends in European countries. Technological Forecasting \& Social Change, 134, 178-185.

DOI: $10.1016 /$ j.techfore.2018.06.002

Dos Santos, M. J. P., \& Diz, H. (2019). Towards Sustainability in European Agricultural Firms. Advances in Intelligent Systems and Computing 783, pp. 161-168.

DOI: $10.1007 / 978-3-319-94709-9 \quad 16$

European Commission (2017) Europa 2020.

http://ec.europa.eu/europe2020/index pt.htm (accessed on October 11, 2019)

EESC opinion on 'Building a sustainable future for aquaculture - A new impetus for the Strategy for the Sustainable Development of European Aquaculture' (OJ C $18,19.1 .2011$, p. 59)

EESC opinion on 'Strategic Guidelines for the sustainable development of EU aquaculture' (OJ C 67, 6.3.2014, p. 150) EESC opinion on 'Removing obstacles to sustainable aquaculture in Europe' (OJ C 34, 2.2.2017, p. 73)

European Parliament resolution of 7 June 2016 on technological solutions for sustainable agriculture in the EU (2015/2225(INI))

Food and Agriculture Organization (2017). Aquaculture Production.

http://data.worldbank.org/indicator/ER.FSH.AQUA.MT?en $\underline{\mathrm{d}=2014 \& \text { start }=1960 \& \text { view }=\text { map }}$ (accessed on October 11, 2019)
Francis, C.; Lieblein, G.; Gliessman, S.; Breland, T.A.; Creamer, N.; Harwood, R.; Salomonsson, L.; Helenius, J.; Rickerl, D.; Salvador, R.; et al. Agroecology: The Ecology of Food Systems. J. Sustain. Agric. 2003, 22, 99-118.

DOI: $\underline{10.1300 / J 064 v 22 n 03 \quad 10}$

Greenfeld, A., Becker, N., Bornman, J. F., Dos Santos, M.J., \& Angel, D. L. (2019). Who will buy fishy lettuce? Australia and Israel as case studies on the potential consumers of aquaponic produce (No. 289581). Agricultural Economics Society. No 289581, 93rd Annual Conference, Warwick University, Coventry, UK https://econpapers.repec.org/paper/agsaesc19/289581.htm (accessed on October 11, 2019)

Goddek, S.; Delaide, B.; Mankasingh, U.; Ragnarsdottir, K.V.; Jijakli, H.; Thorarinsdottir, R. (2015) Challenges of Sustainable and Commercial Aquaponics. Sustainability 7, 4199-4224

DOI: $10.3390 / \mathrm{su} 7044199$

Goddek, S., Joyce, A., Kotzen, B., \& Dos-Santos, M. (2019). Aquaponics and Global Food Challenges. In Aquaponics Food Production Systems (pp. 3-17). Springer, Cham. DOI: $10.1007 / 978-3-030-15943-6 \quad 1$

Hand, C., \& Judge, G. (2012). Searching for the picture: forecasting UK cinema admissions using Google Trends data. Applied Economics Letters 19(11), 1051-1055.

DOI: $\underline{10.1080 / 13504851.2011 .613744}$

IP/B/AGRI/IC/2012-065 "Semi-subsistence farming - value and directions for development". ULP, Centre for Rural Economics at Newcastle University, University of Kent, UK (more leading institutions). European Parliament. https://www.europarl.europa.eu/RegData/etudes/etudes/join/ 2013/495861/IPOL-AGRI_ET(2013)495861_EN.pdf (accessed on October 11, 2019)

Joly, A., Junge, R., \& Bardocz, T. (2015). Aquaponics business in Europe: some legal obstacles and solutions. Ecocycles 1(2), 3-5.

DOI: $10.19040 /$ ecocycles.v1i2.30

Love, D.C.; Uhl, M.S.; Genello, L. (2015). Energy and water use of a small-scale raft aquaponics system in Baltimore, Maryland, United States. Aquac. Eng. 68, 19-27.

DOI: $10.1016 /$ j.aquaeng.2015.07.003

Miličić, V., Ragnheidur, T., Hančič M.T., Dos Santos, M., Hančič, M. T. (2017). Commercial Aquaponics Approaching the European Market: To Consumers' Perceptions of Aquaponics Products in Europe. Water 9(2), 80.

Nichols M, Aquaponics: Where One Plus One Equals Three. Massey University, Palmerston North, New Zealand, Maximum Yield - Indoor gardening, UK January-February 2008. 
Piria, M., Milošević, D., Šprem, N., Mrdak, D., Tomljanović, T., Matulić, D., \& Treer, T. (2016). Condition of European eel from the Adriatic basin of Croatia and Montenegro. 51. hrvatski $i$ 11. međunarodni simpozij agronoma, 15.-18. veljače 2016. godine, Opatija, Hrvatska. Zbornik radova, 269-273.

Rakocy, J. E. (2012). Aquaponics: integrating fish and plant culture. Aquaculture Production Systems 1, 343-386.

Renko, S., Cerjak, M., Haas, R., Brunner, F., \& Tomić, M. (2014). What motivates consumers to buy traditional food products? Evidence from Croatia and Austria using word association and laddering interviews. British Food Journal 116, 1726-1747.

DOI: $\underline{10.1108 / \mathrm{BFJ}-02-2014-0090}$

Kledal, P., Miličič, V., Matulić, D., Dos-Santos, M., \& Cotter, J. (2017). Aquaponics: the ugly duckling in European organic regulation. In Aquaculture Europe 2017-Cooperation for Growth.

Konig, B., Junge, R., Bittsanszky, A., Villarroel, M., \& Kömíves, T. (2016). On the sustainability of aquaponics. Ecocycles 2(1), 26-32.

DOI: $10.19040 /$ ecocycles.v2i1.50

Konig, B., Janker, J., Reinhardt, T., Villarroel, M., \& Junge, R. (2018). Analysis of aquaponics as an emerging technological innovation system. Journal of Cleaner Production 180, 232-243.

DOI: $10.1016 /$ j.jclepro.2018.01.037
Shafahi, M., \& Woolston, D. (2014). Aquaponics: a sustainable food production system. In ASME 2014 International Mechanical Engineering Congress and Exposition (pp. V003T03A073-V003T03A073). American Society of Mechanical Engineers.

Slišković, M., Jelić, G., \& Hell, Z. (2003). Fouling as an indicator of aquaculture influence on environment. Croatian Journal of Fisheries 61(1), 27-32.

https://hrcak.srce.hr/4689

Komives, T., \& Junge, R. (2018). Importance of nickel as a nutrient in aquaponic systems-some theoretical considerations. Ecocycles, 4(2), 1-3.

DOI: $10.19040 /$ ecocycles.v4i2.99

Thorarinsdottir, R. I. (2014). Implementing commercial aquaponics in Europe - first results from the Ecoinnovation project EcoPonics. Aquaculture Europe 14, October 14-17 2014, San Sebastian, Spain

Tomić, M., Matulić, D., \& Jelić, M. (2016). What determines fresh fish consumption in Croatia? Appetite 106, 13-22. DOI: $10.1016 /$ j.appet.2015.12.019

United Nations, (2017). Goals of the Millennium. http://www.unric.org/pt/objetivos-de-desenvolvimentosustentavel/31977-objetivo-8-emprego-digno-ecrescimento-economico (accessed on 1 February 2017).

Villarroel, M., Junge, R., Komives, T., Konig, B., Plaza, I., Bittsánszky, A., \& Joly, A. (2016). Survey of aquaponics in Europe. Water 8(10), 468.

DOI: $\underline{10.3390 / \mathrm{w} 8100468}$ 